\title{
REFLEXIONES DESDE LA EVANGELII GAUDIUM
}

\author{
REFLEXIONS FROM EVANGELII GAUDIUM
}

Raúl Condori Cutimbo*

\begin{abstract}
RESUMEN
En el presente artículo, el autor busca reflexionar sobre la exhortación Evangelii Gaudium, considerando los aspectos fundamentales y resaltantes de este documento. Para tal efecto, se hace un análisis de los cinco núcleos que presenta dicha exhortación. Del mismo modo, se enfatiza la preocupación del Papa Francisco sobre la evangelización y el anuncio de Jesucristo, aspectos que deben transmitirse con la alegría de ser creyente y que necesita darse desde una experiencia personal con Jesucristo.
\end{abstract}

\section{PALABRAS CLAVE}

Alegría, anuncio, Jesucristo, Evangelización, inculturación, preocupación por el hombre.

\begin{abstract}
In this article, the author reflects on the exhortation Evangelii Gaudium, considering the fundamental and important aspects of this document. To this end, he examines the five cores having such exhortation. Similarly, the Pope's concern on evangelization and the proclamation of Jesus Christ, aspects to be transmitted with the joy of being a believer and with a personal experience with Jesus Christ is emphasized.
\end{abstract}

\section{KEY WORDS}

Happiness, Advertisement, Jesus Christ, Evangelization, Inculturation, Concern for man.

* Docente de la Universidad Femenina del Sagrado Corazón: claudiocondoric@unife.pe 


\section{Introducción.}

Al concluir el Año de la Fe, para dar respuesta a las inquietudes del Sínodo realizado en octubre del 2012 denominado "Para la nueva evangelización y la transmisión de la fe" , el Sumo Pontífice Francisco dio a conocer la exhortación apostólica Evangelii Gaudium (EG) ${ }^{1}$ donde plasma el pensamiento y modo de ver de la Iglesia Universal frente a la necesidad de una nueva etapa evangelizadora, marcada por la alegría del evangelio, pero de una manera particular por ser latinoamericano y con toda la experiencia pastoral en los diferentes campos de la vida cotidiana. De allí que se hace necesario comprender su exhortación captando a grandes rasgos el lenguaje de Francisco, para entender el profundo mensaje dado en un lenguaje sencillo para intelectuales o todos aquellos hombres que buscan un encuentro personal con Jesucristo, bautizados que no viven las exigencias de su bautismo, sin pertenencia cordial a la iglesia, los que no conocen a Jesucristo o siempre lo han rechazado.

Llamo lenguaje de Francisco a la forma original en la que Francisco une el contenido, el lenguajey el tono al proclamar el evangelio mediante el lenguaje mixto de los gestos y las palabra donde el lenguaje debe ser el que comprendan los destinatarios para no correr el riesgo de hablar al vacío. El Papa trasmite el mensaje con la gramática de la simplicidad: saluda a todos, toma en brazos a los niños, besa a los enfermos, bendice con la señal de la cruz. Es un icono de la fe expresada en una cultura gestual, afectiva y festiva. Su estilo pastoral es cercano al pueblo por la calidez en el trato y por la sencillez en la predicación. En este marco, la exhortación propone una renovada teología pastoral del anuncio evangelizador o misionero a una cultura con grandes luces y sombras, pero sobretodo necesitada del amor de Dios.

La alegría del Evangelio es un documento muy original en su contenido, forma y estilo, que conjuga líneas teológicas, espirituales y sociales con una neta orientación pastoral. Esta alegría nace de la certeza personal de ser infinitamente amado y del encuentro con Jesucristo que se convierte en feliz amistad. La Iglesia, ya desde el Vaticano II, ha buscado de manera permanente no sólo el "qué" y el "para qué" sino los "cómo" de la evangelización; y esta realidad se vuelve a tomar en las diferentes conferencias episcopales (Medellín, Puebla, Santo Domingo y Aparecida). En la última de manera explícita nos dice que los pastores quieren seguir impulsando la acción evangelizadora, queriendo hacer de sus miembros discípulos y misioneros de Cristo. Desde este contexto nuevamente se asume el tema de la evangelización. El ángulo es ahora muy peculiar: la alegría por querer evangelizar. Francisco es consciente de la situación que pasa el mundo actual y por ello invita a todos los cristianos a enfrentar tal realidad, pero con la alegría que brota del encuentro con Jesucristo y nos dice que "no hay razón para que alguien piense que esta invitación no es para él, porque nadie queda excluido de la alegría reportada por el Señor" (EG 3).

Así el Papa Francisco nos enseña que todo el Pueblo de Dios es el gran sujeto evangelizador (EG 111, 120) y que cada creyente, desde su lugar, está llamado a ser protagonista activo de la misión (EG 119-129). De esta manera la presente

1 El nombre completo del documento es Exhortación apostólica Evangelii Gaudium del Santo Padre Francisco a los obispos, a los presbíteros y diáconos, a las personas consagradas, y a los fieles laicos sobre el anuncio del Evangelio en el mundo actual. 
exhortación no es un documento para especialistas en teología pastoral o algo parecido, sino para todo fiel cristiano que se compromete de manera seria con la misión. Cada uno de nosotros debemos sentirnos cuestionados y debe resonar en nuestros corazones la siguiente expresión: "La misión... no es una parte de mi vida, o un adorno que me puedo quitar; no es un apéndice o un momento más de la existencia. Es algo que yo no puedo arrancar de mi ser si no quiero destruirme. Yo soy una misión en esta tierra, y para eso estoy en este mundo. Hay que reconocerse a sí mismo como marcado a fuego por esa misión de iluminar, bendecir, vivificar, levantar, sanar, liberar. Alli aparece la enfermera de alma, el docente de alma, el político de alma, esos que han decidido a fondo ser con los demás y para los demás" (EG 273).

Por otro lado Francisco siente un aprecio por el documento Evangelii nuntiandi (El anuncio del Evangelio) de Pablo VI que nos dice "Conservemos la dulce y confortadora alegría de evangelizar, incluso cuando hay que sembrar entre lágrimas. Sea ésta la mayor alegría de nuestras vidas entregadas... ( que el mundo actual) pueda así recibir la Buena Nueva no a través de evangelizadores tristes y desalentados, impacientes o ansiosos, sino a través de ministros del Evangelio, cuya vida irradia el fervor de quienes han recibido en sí mismos, la alegría de Cristo y aceptan consagrar su vida a la tarea de anunciar el reino de Dios e implantar la Iglesia en el mundo" (EN 80) porque el primer anuncio o kerigma debe ocupar el centro de la actividad evangelizadora y de todo intento de renovación eclesial.

\section{La exhortación.}

Al abordar la exhortación, nos damos cuenta que es una exhortación claramente personal, a diferencia de lo que sucedió con su primera encíclica Lumen fidei (LF) (iniciada por Joseph
Ratzinger y culminada por Francisco), esto nos hace ver que estamos frente a un Papa que ve la realidad del mundo y de la iglesia de una manera distinta, por la misma experiencia que tuvo en Argentina como obispo de Buenos Aires y más aún por toda la problemática que encierra América Latina. Él ve una realidad con sus errores y sus esperanzas, con sus luces y sombras; y por ello, el tema de fondo es la alegría. ¿Qué alegría? Según el propio Francisco, aquella alegría que surge de la misión de la Iglesia católica en su tarea de llevar el Evangelio hasta los últimos confines del mundo. Una alegría que "se renueva y se comunica" ante el "gran riesgo del mundo actual, con su múltiple y abrumadora oferta de consumo" y una tristeza individualista "que brota del corazón cómodo $y$ avaro, de la búsqueda enfermiza de placeres superficiales, de la conciencia aislada". (EG 2). Es esta la cultura a la que Francisco ha bautizado como Cultura del desecho, de lo pasajero, donde lo más importante es el tener.

Para este tipo de alegría a la que se está refiriendo el Papa, es imprescindible el encuentro personal con Jesucristo que comienza con una toma de decisión para dejarse encontrar por él. Ya desde el Antiguo Testamento se advierte el constante anuncio de la alegría del Señor. Desde los Evangelios nos estimulan diferentes hechos como el saludo del ángel a María, la visita a Isabel y el comienzo del ministerio de Jesús. En estos casos, el evangelio nos narra una alegría que llega a su plenitud. El Papa se pregunta: "¿Por qué no entrar también nosotros en ese río de alegría?". Observa que en nuestra cultura algunos cristianos han hecho la opción "de una Cuaresma sin Pascua" (EG 6). Nos recuerda que, ante las dificultades, "el Señor no ha agotado su ternura" y su amor por los más necesitados, y más ampliamente por todos los hombres y mujeres. Para nosotros es importante la 
cita que hace Francisco de su predecesor remarcando que "llegamos a ser plenamente humanos cuando somos más que humanos, cuando le permitimos a Dios que nos lleve más allá de nosotros mismos para alcanzar nuestro ser más verdadero"(EG 8). Nos remarca que el anuncio es una novedad y un asombro, y que Jesucristo también puede romper los esquemas aburridos en los cuales pretendemos encerrarlo.

La exhortación propone una clara descentralización de gobierno, de manera tal que pueda permitir el desarrollo integral, en diferentes ámbitos y culturas. Para ello, se hace necesario retomar las enseñanzas del Concilio Vaticano II y los últimos documentos de las Conferencias Episcopales. Así el Papa invita a salir y nos dice: atrévanse "a llegar a todas las periferias que necesitan la luz del Evangelio". Reconoce, al mismo tiempo, la libertad de la Palabra que crece sola. Habla de una "intimidad itinerante" de "primerear" y del servicio. Todos estos son temas que desarrolla de manera permanente y transversal en la exhortación. Así mismo la idea del discernimiento, del escuchar a todos, de la necesaria conversión del papado y de la autonomía de las conferencias episcopales.

En una de las partes más originales y estupendas, explica la jerarquía de verdades, tanto en el campo moral como doctrinario, e insiste en simplificar la propuesta cristiana sin perder por ello profundidad y verdad. Porque "la misericordia es la más grande de todas las virtudes". En efecto, a veces el lenguaje ortodoxo puede estar lejos del Evangelio o confundir su verdadero mensaje. Cita a Agustín y a Tomás de Aquino, a los papas recientes, al Concilio y a las Escrituras. Se anima a proponer prudencia y audacia frente a los problemas pastorales más graves, y no se calla ante las situaciones urgentes que aqueja nuestra realidad. Aunque también aclara que "no es función del papa ofrecer un análisis detallado y completo sobre la realidad contemporánea" (EG 51), sin embargo, no deja de hacer críticas muy serias a los modelos económicos y políticos.

La pobreza, la violencia y la falta de respeto a la dignidad humana son los grandes desafíos del mundo actual. Como un profeta denuncia la exclusión, condena la idolatría del dinero y se pone a favor del medio ambiente, de la cultura y de sus creencias. Dice que la inequidad genera violencia y que las guerras están movidas por míseros intereses. Condena la corrupción, los ataques a la libertad religiosa y el relativismo. Se pone en contra de todo fundamentalismo y de las espiritualidades sin Dios. Exige un pensamiento crítico, ataca la burocracia de la Iglesia, advierte sobre la crisis de la familia y llama a sanar heridas. Una y otra vez elogia la religiosidad popular y se manifiesta desconfiado de la globalización y de la tecnología. La mayor amenaza, señala citando a Ratzinger, es "el gris pragmatismo de la vida cotidiana de la Iglesia en la cual aparentemente todo procede con normalidad, pero en realidad la fe se va desgastando y degenerando en mezquindad". (EG, 62) Antes que un teólogo, detrás del texto estamos ante un hombre de profunda fe y de arraigada espiritualidad. Más aún se pregunta, cacaso la misión no debería encarar también el diálogo con la cultura, con la ciencia, con las artes? Quizá donde más sorprende y acierta el documento es en el claro discernimiento a la hora de proponer la gradualidad

2 Primerear, es una expresión exclusiva y propia de Francisco con la que se refiere a involucrarse, acompañar, fructificar y festejar. 
en el campo moral. Allí se advierte la sabiduría del pastor. En esta Exhortación encontraremos a un Papa que muestra sus preocupaciones pastorales, sociales y evangelizadoras desde la experiencia directa con los fieles sin perder la alegría que nace del encuentro con Jesucristo.

\section{Núcleos de la exhortación}

Ahora bien, ¿cuáles son las consecuencias de vivir la alegría del Evangelio? El Papa presenta cinco núcleos donde explica cómo se vive la alegría del Evangelio. A continuación realizaré un recorrido por los cinco núcleos resaltando y reflexionando sobre los principales temas que nos presenta el Papa Francisco:

\subsection{La transformación misionera de la Iglesia.}

El Papa comienza su exhortación dejando en claro que la misión de la Iglesia se da como un llamado de Dios. Es Dios quien primeramente nos ha hecho partícipes de su vida desde la resurrección de Jesús, y nos ha mandado ir por todos los lugares de la tierra para predicar el Evangelio. Es así que la Iglesia va siempre de salida y está siempre invitando a los hombres a participar del Evangelio. Nos exhorta a una impostergable renovación eclesial diciendo: "Sueño con una opción misionera capaz de transformarlo todo, para que las costumbres, los estilos, los horarios, el lenguaje y toda estructura eclesial se convierta en un cauce adecuado para la evangelización del mundo actual más que para la autopreservación"(EG27). La Iglesia como comunidad de creyentes puede llegar a condicionar un dinamismo evangelizador en la medida que se dé el movimiento hacia los hombres, del mismo modo en que Dios se movió para salir al encuentro de los hombres. Es por eso que el cristiano debe perfeccionar su cristianismo yendo hacia las periferias y favoreciendo a las personas que más necesiten de la caridad humana y de la divina. "Cada cristiano y cada comunidad discernirá cuál es el camino que el Señor le pide, pero todos somos invitados a aceptar este llamado: salir de la propia comodidad y atreverse a llegar a todas las periferias que necesitan la luz del Evangelio" (EG. 20). De este modo los cristianos que componen la comunidad eclesial están llamados a plenificarse siendo ejemplo vivo del Evangelio, siendo sal de la tierra y luz del mundo. Por eso el cristiano vive la alegría del Evangelio cuando toma la iniciativa, cuando se involucra, acompaña, fructifica y festeja. La Iglesia que se cierra en su comodidad no cumple con el mandamiento de Cristo de hacer nuevos discípulos y configurarse con Él, por lo que se aleja de la comunidad eclesial. Por tanto, si se conserva en la adhesión a Jesucristo, se mantiene fresca y abierta, lista para ser testimonio vivo de Cristo. Esto significa estar en una renovación constante a fin de permanecer al servicio de los hombres y no de sí misma. Francisco también habla de la importancia de la parroquia como "centro de evangelización y corazón de la comunidad creyente (...) santuario donde los sedientos van a beber para seguir caminando, y centro de constante envío misionero" (EG, 28).

\subsection{En la Crisis del compromiso comunitario.}

En este núcleo el Papa Francisco desarrolla con elocuencia el tema de la exclusión de los pobres en la sociedad y el drama del dinero visto como un fin más que como un medio. Por su experiencia y la atención como pastor de los barrios más desamparados y necesitados de Buenos Aires, Francisco denuncia abiertamente las perversiones del capitalismo y la cómoda pasividad de los cristianos ante las situaciones de sufrimiento de los desprotegidos. Francisco alza su voz de manera particular sobre cuatro puntos específicos: 


\section{a. No a la economía de la exclusión.}

"Así como el mandamiento de "no matar" pone un límite claro para asegurar el valor de la vida humana, hoy tenemos que decir no a una economía de la exclusión y la inequidad". Esa economía mata. No puede ser que no sea noticia que muere de frío un anciano en situación de calle y que sí lo sea la caída de dos puntos en la bolsa. Eso es exclusión. No se puede tolerar más que se tire comida cuando hay gente que pasa hambre. Eso es inequidad (...) Hemos dado inicio a la cultura del "descarte" que, además, se promueve. Ya no se trata simplemente del fenómeno de la explotación y de la opresión, sino de algo nuevo: con la exclusión queda afectada en su misma raíz la pertenencia a la sociedad en la que se vive, pues ya no se está en ella abajo, en la periferia, o sin poder, sino que se está afuera. Los excluidos no son "explotados" sino desechos, "sobrantes". (EG, 53).

\section{b. No a la nueva idolatría del dinero.}

"Una de las causas de esta situación se encuentra en la relación que hemos establecido con el dinero, ya que aceptamos pacíficamente su predominio sobre nosotros y nuestras sociedades. La crisis financiera que atravesamos nos hace olvidar que en su origen hay una profunda crisis antropológica: una negación deliberada del ser humano como valor fundamental $y$ último. Hemos creado nuevos ídolos. (...) La crisis mundial, que afecta a las finanzas y a la economía, pone de manifiesto sus desequilibrios $y$, sobre todo, la grave carencia de su orientación antropológica que reduce al ser humano a una sola de sus necesidades de consumo. (...) iEl dinero es para servir, y no para gobernar! El Papa ama a todos, ricos y pobres, pero tiene la obligación, en nombre de Cristo, de recordar que los ricos deben ayudar a los pobres, respetarlos, promocionarlos. Os exhorto a la solidaridad desinteresada y a una vuelta de la economía y las finanzas a una ética en favor del ser humano" (EG, 55).

\section{c. No a un dinero que gobierna en lugar de servir.}

"La ética suele ser mirada con cierto desprecio burlón. Se considera contraproducente, demasiado humana porque relativiza el dinero y el poder. Se la siente como una amenaza, pues condena la manipulación y la degradación de la persona. En definitiva, la ética lleva a un Dios que espera una respuesta comprometida que está fuera de las categorías del mercado. (...) La ética no ideologizada permite crear un equilibrio y un orden más humano. En este sentido, animo a los expertos financieros y a los gobernantes de los países a considerar las palabras de un sabio de la antigüedad (San Juan Crisóstomo): "No compartir con los pobres los propios bienes es robarles y quitarles la vida. No son nuestros los bienes que tenemos, sino suyos." (EG, 57).

\section{d. No a la inequidad que genera violencia.}

"Hoy en muchas partes se reclama mayor seguridad. Pero hasta que no se reviertan la exclusión y la inequidad dentro de una sociedad y entre distintos pueblos sería imposible erradicar la violencia. Se acusa de la violencia a los pobres y a los pueblos pobres, pero sin igualdad de oportunidades, las diversas formas de agresión $y$ de guerra encontrarán un caldo de cultivo que tarde o temprano provocará su explosión. (...) Algunos simplemente se regodean culpando a los pobres de sus propios males, con indebidas generalizaciones, y pretenden encontrar la solución en una "educación" que los tranquilice y los convierta en unos seres domesticados e inofensivos. Esto se vuelve todavía más irritante si los excluidos ven crecer ese cáncer social que es la corrupción profundamente arraigada en muchos países- en sus gobiernos, empresarios $e$ instituciones-cualquiera que sea la ideología política de sus gobernantes." (EG, 60). Se toma muy en cuenta "algunos desafíos culturales" (61-67), entre los que se encuentran el relativismo, la persecución religiosa, una cultura predominante donde "lo real cede el lugar a la apariencia", una globalización 
que se impone sin respetar la fisonomía cultural de los pueblos, unos nuevos movimientos religiosos que, por un lado tienden al fundamentalismo y por el otro a una espiritualidad individualista sin Dios (EG 63). Refiere a las consecuencias del proceso de secularización que lleva a "una creciente deformación ética, un debilitamiento del sentido del pecado personal y social y un progresivo aumento del relativismo, que ocasionan una desorientación generalizada" (EG 64), a la "crisis cultural profunda" que atraviesa la familia y al estilo de vida individualista que debilita los vínculos.

En ese contexto, señala los "desafíos de la inculturación de la fe" (68-70) y la importancia de evangelizar las culturas para inculturar el Evangelio. También analiza los "desafíos de las culturas urbanas" (71-75), en un novedoso enfoque que señala cómo en la ciudad, lo religioso está mediado por diferentes estilos de vida y la necesidad de "imaginar espacios de oración y de comunión con características novedosas, más atractivas y significativas para los habitantes urbanos" (EG 73). Pide a la Iglesia llegar "allí donde se gestan los nuevos relatos y paradigmas, alcanzar con la Palabra de Jesús los núcleos más profundos del alma de las ciudades" (EG 74). Finalmente presenta los "males urbanos" y la importancia de la Iglesia de vivir a fondo lo humano e introducirse en el corazón de los desafíos.

\subsection{El anuncio del Evangelio.}

El anuncio del Evangelio ha sido encomendado a todo el pueblo. Con los apóstoles se inicia la Iglesia que es comunidad evangelizadora que siempre está saliendo al encuentro de los hombres para presentarle a Cristo con su ejemplo de vida. El ser Iglesia es principalmente ser pueblo de Dios. En ella, todos están llamados a sentirse cerca del Padre a través de Jesús y en la unidad que da el Espíritu Santo. Es el Espíritu el que mueve a los hombres a ser una Iglesia tomando en cuenta las diferentes culturas de los pueblos. De modo que la cultura no es un obstáculo para la evangelización. Sobre esto dice el Papa Francisco que la gracia supone la cultura, pues es en ella donde la fe crece y es gracias a los símbolos de la cultura que la fe se hace familiar y cercana a los hombres. De este modo, el Papa Francisco aclara que la multiculturalidad y la pluriculturalidad no son un riesgo para al Evangelio, sino que son la base natural de la sociedad en la que la fe se origina y se desarrolla.

La Buena Noticia, ha sido propagada a través de la palabra. Es Cristo, la Palabra del Padre quien nos salva. Por eso la reflexión sobre la palabra, viva en Cristo, y escrita en los Textos Sagrados es el centro de la vida de la Iglesia. De hecho, por la convicción que generan los predicadores del Evangelio, los cristianos han encontrado un apoyo para el surgimiento de la fe. El Papa hace énfasis en la centralidad de la predicación del Evangelio. La predicación, dice el Papa, es el momento del diálogo entre Dios y su pueblo donde el predicador es el mediador. La predicación nace del amor a Dios, a la Escritura y al pueblo de Dios. Es por eso que el predicador debe preparar su homilía para que sea una renovación del Mensaje que Dios da a su pueblo y un encuentro personal con Cristo para cada creyente.

Cada uno de los bautizados, cualquiera que sea su función en la Iglesia y el grado de ilustración de su fe, es un agente evangelizador y sería inadecuado pensar en un esquema de evangelización llevado adelante por actores calificados donde el resto del pueblo fiel sea sólo receptivo de sus acciones $(E G, 120)$. No se puede separar el anuncio de la salvación del amor fraterno. La misión pide la salida de sí hacia el hermano: caridad efectiva con el prójimo. 


\subsection{La dimensión social de la Evangelización.}

"Evangelizar es hacer presente en el mundo el Reino de Dios". Pero, "ninguna definición parcial o fragmentaria refleja la realidad rica, compleja y dinámica que comporta la evangelización, si no es con el riesgo de empobrecerla e incluso mutilarla". Ahora, dice Francisco "quisiera compartir mis inquietudes acerca de la dimensión social de la evangelización precisamente porque, si esta dimensión no está debidamente explicitada, siempre se corre el riesgo de desfigurar el sentido auténtico e integral que tiene la misión evangelizadora." (EG, 176). En esta parte de la exhortación el Papa Francisco desarrolla el tema del abandono de los pobres, los débiles, los ancianos, y los más vulnerables. Indica que la predicación del Evangelio, tiene un contenido social cuyo centro es la caridad. Esta caridad de la que habla el Papa no es la ayuda temporal o sobrante que podamos dar, sino el verdadero compromiso en el mejoramiento de la situación de los hombres que brota del reconocer que cada uno de ellos "ha sido elevado al corazón mismo de Dios" (EG, 177) Una de las consecuencias de este reconocimiento es la inclusión social de los pobres según una intención que desee emplearlos y ver en ellos fines y no medios de consumo o de mercado. Podemos decir que el Papa Francisco llama a construir una economía que tenga como base el reconocimiento del hombre como fin y no como medio, donde la plenitud de las personas traiga el bien común y la paz social que estén fundamentados en la justa repartición de la riqueza y la valoración de la dignidad de las personas. La redención tiene sentido social: redime a la persona y a sus relaciones sociales. Quien acepta el kerigma, desea, busca y cuida el bien de los demás.

\subsection{Evangelizadores con espíritu.}

"Evangelizadores con espíritu quiere decir evangelizadores que se abren sin temor a la acción del Espiritu Santo. En Pentecostés, el Espíritu hace salir de sí mismos a los Apóstoles y los transforma en anunciadores de las grandezas de Dios, que cada uno comienza a entender en su propia lengua. (...) Invoquémoslo hoy, bien apoyados en la oración, sin la cual toda acción corre el riesgo de quedarse vacía y el anuncio finalmente carece de alma. Jesús quiere evangelizadores que anuncien la Buena Noticia no sólo con palabras, sino sobre todo con una vida que se ha transfigurado en la presencia de Dios." (EG, 259). Evangelizar significa dignificar que implica el desarrollo integral, la integración plena a la sociedad, la solidaridad y el criterio de autenticidad evangélica. Es espiritualidad que transforma y compromete, es el amor de Jesús que nos salva y le da sentido a todo; es buscar el gusto espiritual de estar cerca del pueblo, en el corazón del pueblo. Con el Espíritu Santo, enviado como regalo en medio del pueblo siempre está María, el estilo mariano en la evangelización dará equilibrio entre justicia - ternura y contemplación - acción.

\section{A modo de conclusión.}

El Papa Francisco con esta Exhortación compromete de manera radical a todos los hombres, pero de manera especial a los creyentes, a tener una mirada distinta sobre la realidad que nos toca vivir; una mirada centrada en las verdaderas necesidades y problemas que tiene todo ser humano. También nos invoca a no descuidar ninguna de las esferas en las que el hombre se encuentra. Tiene una clara conciencia de que la evangelización es y debe ser integral y por ello se hace urgente entrar en diálogo con la cultura, la ciencia, la política; tener un sentido ecuménico, es decir que debemos inculturar el evangelio en todas las culturas del mundo moderno. 
Por otro lado se advierte un aporte original de la Iglesia latinoamericana a la comunidad cristiana universal, un aporte donde se piensa en la integración de la promoción humana, el desarrollo integral y la liberación histórica en el acto y en el mensaje evangelizador. Esta contribución se encuentra presente, de manera consciente y reflexionada desde la II Conferencia de Medellín, luego presente de modo explícito en la Evangelii nuntiandi de Pablo VI, hasta la influencia de la IV Conferencia de Aparecida, a través de Bergoglio, hoy Francisco, en su exhortación Evangelii gaudium. Así mismo nos invita a ser los evangelizadores desde el encuentro personal con Jesucristo y tener la experiencia de la verdadera alegría que brota del corazón mismo de Jesucristo, por ello afirma que "no es lo mismo tratar de construir el mundo con su Evangelio que hacerlo sólo con la propia razón (...) El verdadero misionero (...) sabe que Jesús camina con él, habla con él, trabaja con él". (EG, 266). Para culminar debemos reconocer que el mensaje que nos entrega el Papa Francisco es un mensaje fuerte, sencillo, alentador y directo con una profunda humanidad y respeto al otro; y nos invita, como él mismo lo ha demostrado, más que a hablar, a ir hacia los demás creando vínculos de comunión e irradiando alegría en nuestras relaciones con el prójimo, es decir actuar desde el testimonio de vida para crear esa nueva cultura de paz y respeto.

\section{REFERENCIA}

Francisco (2013) Evangelii gaudium. Lima: Ed. Paulinas.

Concilio Vaticano II. Documentos completos (2008). Lima: Ed. Paulinas.

Pablo VI (1975). Evangelii nuntiandi. Lima: Ed. Salesiana.

Santo Domingo conclusiones (1992). Lima: CEP.

Juan Pablo II (1999). Iglesia en América. Lima: MJR.

Aparecida (2007). Lima: CEP.

Congar Y. (1998). Jesucristo. Barcelona: Ed. Estela.

Boff. L. (1997). Iglesia: carisma y poder. Santander: Sal Terrae. 
